\title{
Avaliação do potencial de utilização da escória granulada de fundição em concreto autoadensável
}

\author{
Evaluation of granulated foundry slag in self-compacting \\ concrete
}

\begin{abstract}
Francieli Tiecher
Paulo Manuel

Daniel Tregnago Pagnussat

Denise Carpena Coitinho Dal Molin Angela Borges Masuero

\section{Resumo}

${ }^{1}$ Francieli Tiecher

${ }^{1}$ Faculdade Meridional Passo Fundo - RS - Brasil

2 Paulo Manuel

${ }^{2}$ Departamento de Engenharia da Província de Luanda Ilha do Cabo - Luanda - Angola

${ }^{3}$ Daniel Tregnago Pagnussat ${ }^{3}$ Universidade Federal do Rio Grande

Tramandaí - RS - Brasil

${ }^{4}$ Denise Carpena Coitinho Dal

Molin

${ }^{4}$ Universidade Federal do Rio Grande

do Sul

Porto Alegre - RS - Brasil

${ }^{5}$ Angela Borges Masuero 5 Universidade Federal do Rio Grande do Sul Porto Alegre - RS - Brasil

Recebido em 17/06/17

Aceito em 06/06/18

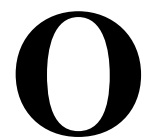

presente estudo propõe um novo uso para a escória granulada de fundição: contribuir para a obtenção da viscosidade adequada em concretos autoadensáveis. Nesse tipo de concreto, em função de sua elevada fluidez, comumente são relatados problemas de segregação e, para contorná-los, podem ser utilizados fillers. A escória granulada é um resíduo oriundo da produção do ferro fundido. O grande volume gerado é problema para a indústria da fundição, que tem elevados custos para efetuar seu descarte de maneira adequada. A fim de propor um emprego para esse resíduo, garantindo benefícios tanto para a indústria que o gera quanto para a construção civil, o presente estudo tem como objetivo avaliar o emprego da escória granulada de fundição moída como modificador de viscosidade em concretos autoadensáveis, minimizando a potencialidade de segregação desse tipo de concreto. Os resultados obtidos mostram que a escória granulada de fundição moída possibilita a obtenção de concretos autoadensáveis sem segregação e com fluidez adequada. Além disso, tanto para as propriedades mecânicas quanto para a avaliação de durabilidade houve melhora com o emprego do resíduo, o que torna viável seu emprego para o fim proposto.

Palavras-chave: Escória granulada de fundição. Concreto autoadensável. Durabilidade.

\section{Abstract}

This study proposes a new use for granulated slag foundry: its application as a viscosity modifier in self-compacting concrete. During the production of cast iron, one of the main waste products coming from the granulate is slag. The large volume generated is a problem for the foundry industry, which incurs in high costs to carry out its disposal properly. This is the kind of waste that presents pozzolanic activity and, therefore, can be used as a substitute for Portland cement. However, the building industry has not yet taken advantage of this waste property, since other pozzolanic materials are still more traditional (fly ash, blast furnace slag, among others). Due to their high fluidity in self-compacting concretes, segregation problems are commonly reported. The use of cast granulated slag as a viscosity modifier, minimizing its segregation potential, was evaluated in this study. The results show that this waste makes it possible to obtain self-compacting concretes with adequate viscosity. In addition, it improved mechanical and durability properties, making feasible the use of this residue for the proposed ends.

Keywords: Granulated foundry slag. Self-compacting concrete. Durability.
\end{abstract}

TIECHER, F.; MANUEL, P.; PAGNUSSAT, D. T.; DAL MOLIN, D. C. C.; MASUERO, A. B. Avaliação do potencial de 


\section{Introdução}

A indústria da fundição é um setor importante para a economia brasileira. De acordo com a Associação Brasileira de Ferro Fundido e Aço (ASSOCIAÇÃ̃O BRASILEIRA DAS INDÚSTRIAS..., 2017), a produção anual de ferro fundido no Brasil está em torno de 1.773 .578 toneladas.

Os principais resíduos gerados no processo de fundição são areia de fundição, escória de fundição, pó de exaustão (proveniente da preparação da areia, da desmoldagem das peças de ferro fundido, do forno de fusão e da limpeza das peças de usinagem), lama do tratamento da água de refrigeração e cavaco de usinagem. Porém, desses resíduos os que são gerados em maior volume são areia de fundição e escória de fundição, nessa ordem.

A escória granulada de fundição (EGF) surge a partir do processo de fabricação do ferro fundido por meio do forno cubilô, de onde é vazada, ainda quente, por um canal de água corrente, para receber um resfriamento brusco. Esse resfriamento da EGF líquida faz com que ela se solidifique em um formato granulado. $\mathrm{O}$ material granulado adquire propriedades vítreas (amorfiza), o que potencializa sua utilização aglomerante, uma vez que o índice de atividade pozolânica é superior a 90\%, como mostram os estudos de Cecatto (2003), Rescke (2003), Stroup, Stroup e Fallin (2003) e Pagnussat (2004). O estudo de Stroup, Stroup e Fallin (2003) gerou uma patente para o uso desse resíduo na fabricação de cimento, tendo sido verificado que a EGF melhora a resistência mecânica em concretos com idades mais avançadas, como também inibe o desencadeamento da reação álcali-agregado e evita $\mathrm{o}$ ataque por sulfatos.

Considerando-se que o volume gerado do resíduo EGF é bastante expressivo, em torno de $8 \mathrm{mil}$ toneladas ao mês (ASSOCIAÇÃO BRASILEIRA DAS INDÚSTRIAS..., 2017), o estudo de outras potencialidades para seu emprego mostra-se importante tanto sob aspectos ambientais quanto econômicos. Nesse sentido, trabalhos mostram que o emprego da EGF como agregado em concretos e argamassas propicia misturas compatíveis às obtidas com agregados tradicionais (UKPAKA, 2016; TORRESA; BARTLETTB; PILGRIMA, 2017; PATILL; MEHETRE; PHALAK, 2015).

O emprego de fillers provenientes de resíduos em concretos autoadensáveis (CAA) vem sendo bastante estudado. Em geral, para controlar a segregação do CAA, empregam-se aditivos químicos modificadores de viscosidade, contudo os fillers têm demonstrado melhor custo-benefício nesse papel, substituindo, por isso, esse tipo de aditivo. Os fillers podem evitar a segregação dos concretos de elevada fluidez e também conferir ganhos na durabilidade e na resistência (TAKADA, 2004; KHAN; SHARMA, 2015; LEUNGA et al., 2016). Além disso, o emprego de fillers provenientes de resíduos traz benefícios ambientais (YUNG; YUNG; HUA, 2013; RANJBAR, 2015; ATTACHAIYAWUTH et al., 2016; GARG, 2016).

O estudo aqui proposto tem como objetivo avaliar o comportamento da EGF moída quando adicionada como filler para auxiliar no alcance da viscosidade adequada para a obtenção de concretos autoadensáveis (CAA), minimizando o potencial de segregação que existe nesse tipo de concreto. Além disso, o trabalho avalia se características de resistência à compressão e durabilidade do CAA contendo filler de EGF são compatíveis com as obtidas em concretos convencionais.

\section{Materiais e métodos}

O programa experimental deste trabalho envolveu a seleção, a caracterização e a preparação dos materiais para produção de CAA com incorporação de EGF, e também de concreto convencional (CCV) de referência. A seguir são apresentados os materiais e os métodos empregados no estudo.

\section{Materiais}

Para a confecção dos concretos, além da EGF, foram empregados os seguintes materiais: cimento Portland pozolânico CPIV-32, cujas características são apresentadas na Tabela 1 , obtidas por meio de fluorescência de raios $\mathrm{X}$; areia quartzosa de rio e brita basáltica (características descritas Tabela 2, obtidas através dos ensaios preconizados nas normas técnicas NBR 7211 (ABNT, 2009a), NBR NM 52 (ABNT, 2009b) e NBR NM 53 (ABNT, 2009c); aditivo superplastificante de terceira geração à base de policarboxilatos; e água da rede pública de abastecimento.

\section{Escória granulada de fundição}

Quando se emprega qualquer resíduo na fabricação de um subproduto, é importante a avaliação das alterações de propriedades físicas, mecânicas e de durabilidade que possam ser afetadas. No caso da EGF, a classificação, de acordo com a NBR 10004 (ABNT, 2004), é de resíduo inerte (Classe III). 
Tabela 1 - Características do cimento Portland pozolânico CP IV-32

\begin{tabular}{c|c}
\hline Compostos & Teor (\%) \\
\hline $\mathrm{SiO}_{2}$ & 37,73 \\
\hline $\mathrm{Al}_{2} \mathrm{O}_{3}$ & 14,76 \\
\hline $\mathrm{Fe}_{2} \mathrm{O}_{3}$ & 3,95 \\
\hline $\mathrm{CaO}$ & 34,14 \\
\hline $\mathrm{MgO}$ & 2,43 \\
\hline $\mathrm{K} 2 \mathrm{O}$ & 2,47 \\
\hline $\mathrm{Na}_{2} \mathrm{O}$ & 0,02 \\
\hline $\mathrm{SO}_{3}$ & 1,96 \\
\hline $\mathrm{CO}_{2}$ & 2,54 \\
\hline Massa específica $\left(\mathrm{kg} / \mathrm{dm}^{3}\right)=2,71$ \\
\hline Diâmetro médio das partículas $(\mu \mathrm{m})=11,85$ \\
\hline \multicolumn{2}{c}{ Perda ao fogo $=1,90$} \\
\hline
\end{tabular}

Tabela 2 - Características dos agregados miúdo e graúdo

\begin{tabular}{c|c|c}
\hline Características & Agregado miúdo & Agregado graúdo \\
\hline Dimensão máxima característica $(\mathrm{mm})$ & 4,80 & 19,00 \\
Módulo de finura & 2,89 & 6,90 \\
Massa específica $\left(\mathrm{kg} / \mathrm{dm}^{3}\right)$ & 2,60 & 2,82 \\
\hline
\end{tabular}

Os ensaios de caracterização ambiental (lixiviação e solubilização) de concretos confeccionados com a EGF foram realizados em estudo anterior, por Reschke (2003), em concretos com teor de substituição de 50\% do cimento pela EGF, e relação água-aglomerante 0,7 , ou seja, bastante susceptíveis à liberação de compostos deletérios. Os resultados mostraram que, sob essa condição, o resíduo também pode ser considerado inerte.

Conforme relatado anteriormente, vários estudos já constataram o caráter amorfo da EGF e seu potencial de utilização como substituto do cimento em concretos, bem como seu índice de atividade pozolânica (MOOSHER, 2013; DINAKAR; SETHY; SAHOO, 2013; PATILL; MEHETRE; PHALAK, 2015). Contudo, verificou-se que a EGF empregada neste estudo, quando in natura, possui composição granulométrica bastante semelhante à da areia natural, ou seja, com dimensão máxima característica de 4,8 mm, módulo de finura de 3,70 e massa específica de $2,76 \mathrm{~g} / \mathrm{cm}^{3}$ (condição seca) (Figura 1a). Porém, para esta pesquisa a EGF foi empregada como um filler para que minimizasse o potencial de segregação que comumente ocorre em CAA. Para tanto, a EGF foi previamente submetida a um processo de moagem em moinho de bolas durante $40 \mathrm{~min}$, que resultou em partículas com diâmetro médio igual a $115,30 \mu \mathrm{m}$ e massa específica de $2,70 \mathrm{~g} / \mathrm{cm}^{3}$ (Figura 1b).

A composição química da EGF empregada está apresentada na Tabela 3 e foi obtida através da análise por fluorescência de raios X.

\section{Métodos}

\section{Dosagem dos concretos}

O CCV foi obtido através do método de dosagem do IPT/Epusp (HELENE; TERZIAN, 1992). Estipulou-se um abatimento de tronco de cone (ABNT, 2015) de $(80,0 \pm 10,0) \mathrm{mm}$, obtendo-se um teor de argamassa de $55 \%$.

Por sua vez, o CAA foi dosado pelo método proposto por Tutikian e Dal Molin (2015). Conforme o que é proposto pelo método, um superplastificante é utilizado para aumentar sua fluidez do concreto, e um material fino é colocado na mistura para propiciar aumento na viscosidade, evitando a segregação e tomando-se cuidado para que o concreto consiga preencher os espaços da forma, atendendo às características preconizadas na NBR 15823 (ABNT, 2010a, 2010b, 2010c, 2010d, 2010e).

Os ensaios realizados para avaliar essas características e determinar os teores ideais de EGF e de aditivo do CAA foram Slump Flow Test (ABNT, 2010b), T500mm (ABNT, 2010e), Funil V (V-funnel) (ABNT, 2010d) e Caixa L (L-box) (ABNT, 2010c). Conforme o que é proposto pelo método de Tutikian e Dal Molin (2015), a avaliação da viscosidade adequada do concreto foi feita visualmente, a partir dos ensaios realizados para caracterização do CAA no estado fresco. 
Figura 1 - Aspectos da EGF resfriada e depois de moída

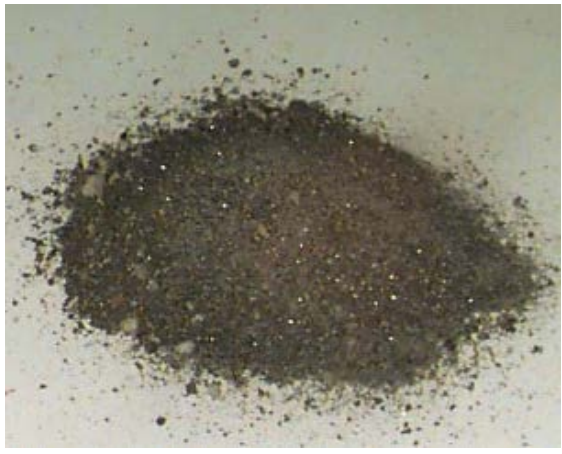

(a) Após resfriamento brusco

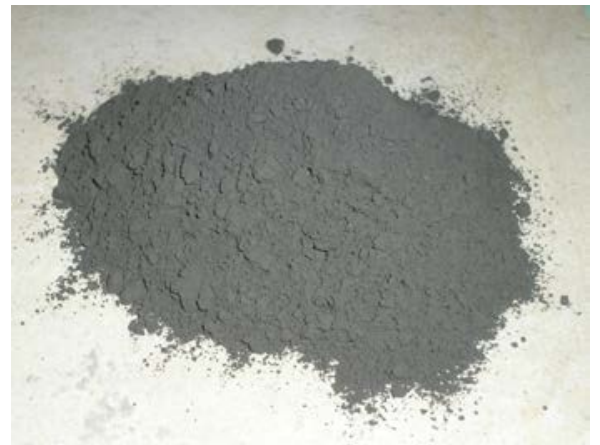

(b) Após processo de moagem

Tabela 3 - Composição química da EGF

\begin{tabular}{c|c}
\hline Compostos & Teor (\%) \\
\hline $\mathrm{SiO}_{2}$ & 53,52 \\
\hline $\mathrm{Al}_{2} \mathrm{O}_{3}$ & 9,97 \\
\hline $\mathrm{CaO}$ & 18,98 \\
\hline $\mathrm{MgO}$ & 9,91 \\
\hline $\mathrm{FeO}$ & 3,2 \\
\hline $\mathrm{MnO}$ & 3,26 \\
\hline $\mathrm{P}_{2} \mathrm{O}_{5}$ & 0,02 \\
\hline $\mathrm{S}$ & 0,66 \\
\hline $\mathrm{Cr}_{2} \mathrm{O}_{3}$ & 0,14 \\
\hline $\mathrm{V}_{2} \mathrm{O}_{5}$ & 0,04 \\
\hline $\mathrm{TiO}_{2}$ & 0,63 \\
\hline$\sum\left(\mathrm{SiO}_{2}, \mathrm{Al}_{2} \mathrm{O}_{3}, \mathrm{Fe}_{2} \mathrm{O}_{3}\right)$ & 63,49 \\
\hline $\mathrm{Classificação}$ & Classe E \\
\hline
\end{tabular}

Assim, o teor de aditivo ajustado pelo método para atender às características do CAA no estado fresco foi de $0,66 \%$ sobre a massa do cimento (percentual calculado em função do teor de sólidos do material, fazendo-se os devidos ajustes da a/c). A EGF foi ajustada em um teor de 35\% (em substituição à massa de agregado miúdo).

Tanto para o CCV, quanto para o CAA foram estudadas três famílias de concretos, 1:3, 1:4,5 e 1:6 (cimento:agregados+EGF, em massa), que resultaram nos traços apresentados na Tabela 4.

Os ensaios de resistência à compressão foram realizados conforme a NBR 5739 (ABNT, 2007) aos 7, 14 e 28 dias, sendo ensaiados 3 corpos de prova por idade.

Foram adotados dois métodos para estudar a durabilidade dos concretos produzidos: absorção de água por capilaridade, através do método desenvolvido por Kelhan (1988); e penetração de cloreto, através do ensaio preconizado pela C 1202 (AMERICAN..., 2012).

\section{Absorção de água por capilaridade}

Conforme mencionado anteriormente, a avaliação da absorção de água por capilaridade foi efetuada através do método desenvolvido por Kelhan (1988). O ensaio foi realizado com a utilização de 2 corpos de prova cilíndricos, com 25 mm de espessura e 100 mm de diâmetro, por traço de concreto $(1: 3 ; 1: 4,5$; 1:6). Portanto, foram ensaiados 6 corpos de prova para cada tipo de concreto, totalizando 18 corpos de prova.

Os corpos de prova com as dimensões preconizadas para a realização do ensaio foram obtidos através da corte de corpos de prova maiores (100 mm x 200 $\mathrm{mm})$ aos 28 dias de idade.

O método é baseado na penetração de água no concreto (não saturado) ao longo do tempo por meio de sucção capilar por somente uma das faces do corpo de prova, efetuando-se a medição da massa aparente ao longo do tempo em corpos de prova mantidos submersos. Desse modo, a parte do fundo da forma cilíndrica foi escolhida para ficar em contato direto com a água. A Figura 2 ilustra o ensaio em andamento. 
Tabela 4 - Traços dos concretos empregados no estudo

\begin{tabular}{c|c|c|c|c|c|c}
\hline Tipo de & Família de & \multicolumn{6}{|c}{ Traço unitário } \\
\cline { 3 - 7 } concreto & concreto & Cimento & Areia & EGF & Brita & Água \\
\hline \multirow{3}{*}{ CCV } & 3 & 1 & 1,2 & - & 1,8 & 0,42 \\
& 4,5 & 1 & 2,0 & - & 2,5 & 0,49 \\
& 6 & 1 & 2,8 & - & 3,2 & 0,59 \\
\hline \multirow{3}{*}{ CAA } & 3 & 1 & 0,8 & 0,4 & 1,8 & 0,38 \\
& 4,5 & 1 & 1,3 & 0,7 & 2,5 & 0,47 \\
& 6 & 1 & 1,8 & 1,0 & 3,2 & 0,57 \\
\hline
\end{tabular}

Figura 2 - Amostras submersas durante o ensaio de absorção por capilaridade
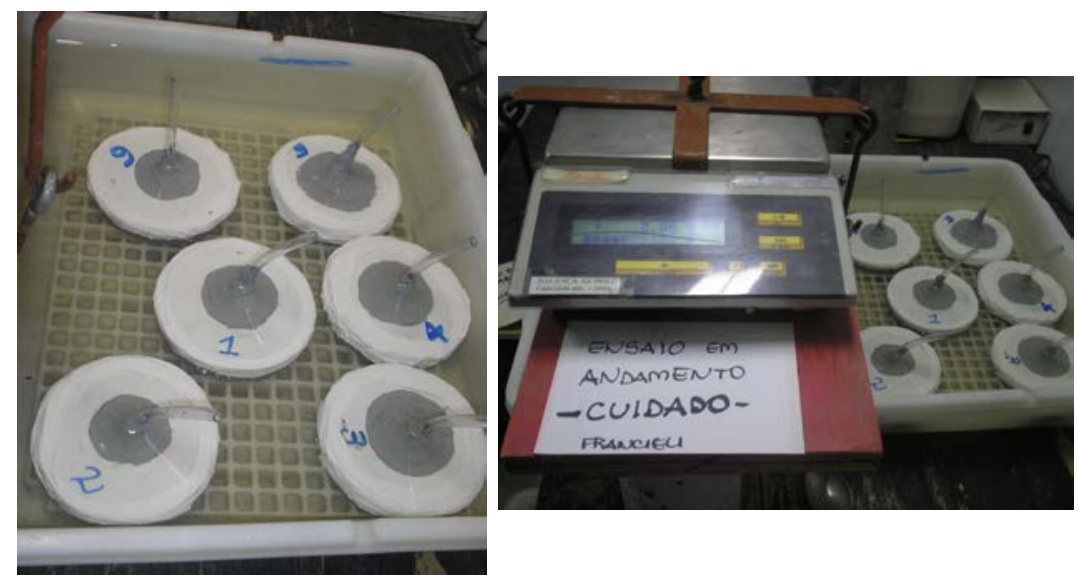

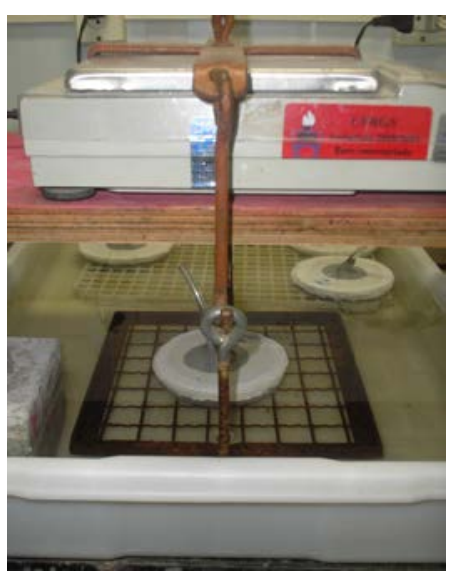

Ao final do ensaio plotam-se curvas com os ganhos de massa em relação à raiz quadrada do tempo para cada corpo de prova. Nessas curvas puderam ser verificadas duas fases distintas: uma de absorção inicial e uma de saturação do corpo de prova. A partir dos resultados é possível calcular a resistência capilar dos concretos, em h/m², e a taxa de absorção, em $\mathrm{g} / \mathrm{cm}^{2} \cdot \mathrm{h}^{1 / 2}$.

\section{Penetração de íons cloreto}

O ensaio preconizado pela C 1202 (AMERICAN..., 2012) foi adotado para avaliar a penetração de cloreto nos concretos ensaiados. Trata-se de um ensaio acelerado no qual se realizam medições de correntes elétricas passantes em corpos de prova de concreto ao longo do tempo e que, de acordo com a norma, podem ser um indicativo da habilidade do concreto em resistir à penetração de íons cloreto.

Para este ensaio foram utilizados 2 corpos de prova de concreto por traço $(1: 3 ; 1: 4,5 ; 1: 6)$ para cada tipo de concreto, totalizando 18 corpos de prova ensaiados. Os corpos de prova possuíam $100 \mathrm{~mm}$ de diâmetro e $50 \mathrm{~mm}$ de espessura, os quais, assim como os corpos de prova do ensaio de absorção capilar, foram obtidos pelo corte de corpos de prova cilíndricos de dimensões 100 mm x 200 mm.
Salienta-se que foram utilizadas amostras de 2 corpos de prova diferentes, retirados do centro de 2 corpos de prova maiores (100x200 mm), e o ensaio em si de penetração de cloreto foi realizado aos 28 dias de idade dos concretos.

As medidas das correntes elétricas foram feitas a cada 30 min durante um período de 6 h. A Figura 3 mostra todo o sistema montado durante a realização do ensaio.

A última etapa do ensaio consistiu em calcular a carga total passante (Q), em Coulombs, dos corpos de prova para a classificação dos concretos com relação à facilidade de penetração de íons cloreto, através da Equação 1.

$\mathrm{Q}=900\left(\mathrm{I}_{0}+2 \mathrm{I}_{30}+2 \mathrm{I}_{60}+\ldots+2 \mathrm{I}_{330}+\mathrm{I}_{360}\right) \quad$ Eq. 1

Onde:

$\mathrm{Q}=$ carga total passante (Coulombs);

$\mathrm{I}_{0}=$ corrente imediatamente após a aplicação da DDP; e

$\mathrm{I}_{\mathrm{t}}=$ corrente no instante $\mathrm{t}$ (minutos) após a aplicação da DDP.

De posse dos valores de Q efetuou-se a classificação da penetração de cloreto, de acordo com a Tabela 5. 


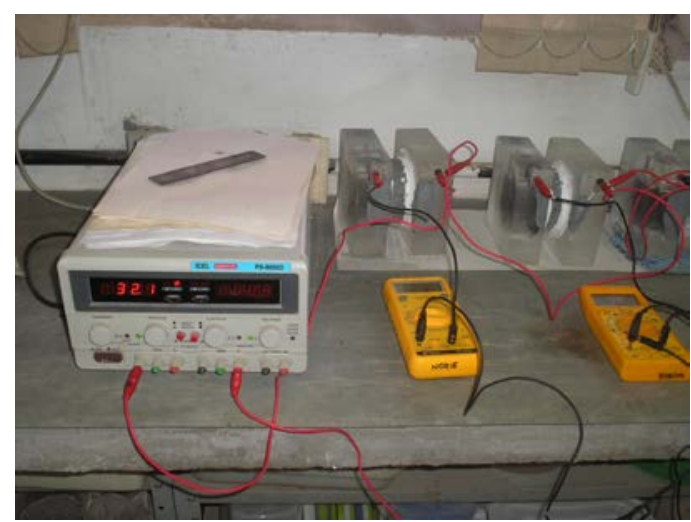

(a) ensaio sendo realizado

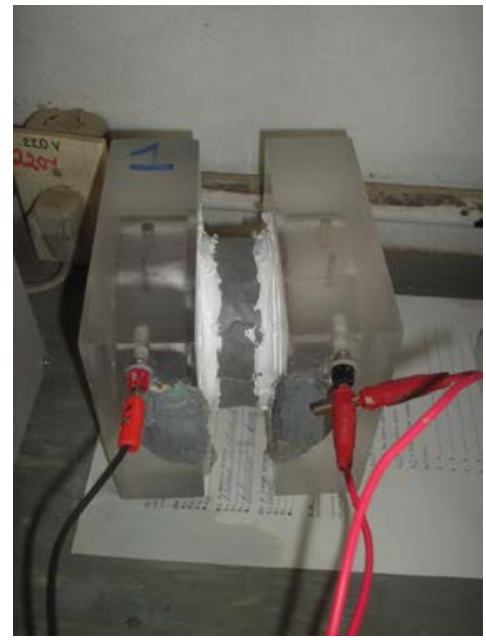

(b) Detalhe da montagem das células

Tabela 5 - Classificação da ASTM C 1202 (AMERICAN..., 2012) quanto à facilidade de penetração de íons cloreto

\begin{tabular}{c|c}
\hline Carga passante (Coulombs) & Penetração de íons cloreto \\
\hline > 4000 & Alta \\
2000 a 4000 & Moderada \\
1000 a 2000 & Baixa \\
100 a 1000 & Muito baixa \\
$<100$ & Desprezível \\
\hline
\end{tabular}

\section{Resultados e discussões \\ Dosagem, ensaios no estado fresco e resistência à compressão}

A respeito da dosagem realizada no presente estudo para obtenção de CAA empregando um fino residual, pode-se dizer que, em relação a outros estudos que empregaram materiais residuais em pó como modificadores de viscosidade, substituindo os agregados miúdos, para evitar a segregação dos CAAs, o percentual empregado neste trabalho é alto, 35\%. Esse percentual foi obtido a partir do método de dosagem empregado, mas, em geral, o valor adotado por outros autores gira em torno de 20\% (SUA-IAMA; MAKUL, 2013; UYGUNOGLUA; TOPÇUB; ÇELIKC, 2014). Contudo, é preciso ponderar a respeito das comparações diretas em relação ao teor de substituição de fillers entre diferentes estudos, uma vez que os materiais empregados possuem características e composições distintas.

Na Tabela 6 são apresentados os resultados dos ensaios no estado fresco para os CAAs em comparação com os valores de referência apresentados pela NBR 15823 (ABNT, 2010a, 2010b, 2010c, 2010d, 2010e) para esse tipo de concreto. Observa-se que os CAAs produzidos neste estudo, empregando EGF, apresentaram espalhamento adequado e mostraram-se suficientemente fluidos para ultrapassar armaduras sem segregar, e em um tempo considerado adequado. Isso permite dizer que foi possível a obtenção de CAAs com as características adequadas e desejáveis para esse tipo de concreto.

As Figuras 4 e 5 apresentam os diagramas de dosagem do CCV e do CAA respectivamente.

Através dos diagramas de dosagem verifica-se que o CAA consumiu menor quantidade de cimento que o CCV. Isso também pode ser mais bem observado na Figura 6, que foi obtida a partir da idade de 28 dias dos concretos. Como as resistências obtidas foram praticamente equivalentes, pode-se atribuir a redução desse consumo à maior compacidade do CAA em relação ao CCV, uma vez que foi feita a substituição de agregado miúdo por um material com finura compatível ao cimento. Sendo assim, temos no CAA um teor de materiais finos e de pasta bem maiores que o $\mathrm{CCV}$, e esses teores aumentam à medida que se aumenta a resistência.

Na Figura 6, em relação às resistências à compressão, nota-se ainda que o efeito filler propiciado pela EGF nos CAAs é mais significativo quanto menores são as resistências dos concretos, ou seja, para $20 \mathrm{MPa}$, diferença das resistências do 
CAA e do CCV de 16\%; para $25 \mathrm{MPa}$, diferença de $13 \%$; para $30 \mathrm{MPa}$, diferença de $10 \%$; e para 35 $\mathrm{MPa}$, diferença de $6 \%$. Esse comportamento pode ser explicado pelo fato de os concretos com resistências maiores também possuírem maiores consumos de cimento, logo o efeito filler, nesse caso, não se sobressai tanto, prevalecendo as características de ganho de resistência do cimento presente nas misturas.

\section{Ensaios de durabilidade}

O ensaio desenvolvido por Kelhan (1988) foi utilizado para avaliação da facilidade de absorção de água dos concretos. De acordo com o método, a partir dos valores de absorção obtidos ao longo do tempo, plotam-se gráficos, com os quais se obtêm as equações para o cálculo da taxa de absorção e da resistência capilar. Ambos, taxa de absorção e resistência capilar, são os parâmetros para avaliação dos concretos.

A fim de ilustrar a etapa da construção dos gráficos para a obtenção das equações experimentais de cada concreto, a Figura 7 apresenta os gráficos de ajuste para o traço 1:6 do CCV e do CAA. Salienta-se que o ponto onde a reta muda de inclinação (nick point) situa-se no momento em que o concreto sai da fase de absorção para a fase de saturação.

Tabela 6 - Resultados obtidos nos ensaios realizados com os CAAs no estado fresco

\begin{tabular}{|c|c|c|c|c|c|c|c|c|}
\hline \multirow{2}{*}{$\begin{array}{l}\text { Traço } \\
(\mathbf{k g} / \mathbf{k g})\end{array}$} & \multicolumn{2}{|c|}{$\begin{array}{c}\text { Abatimento/ } \\
\text { Espalhamento (mm) }\end{array}$} & \multicolumn{2}{|c|}{$\begin{array}{l}\mathbf{T}_{500} \\
\text { (s) }\end{array}$} & \multicolumn{2}{|c|}{$\begin{array}{l}\text { V-funnel } \\
\text { (s) }\end{array}$} & \multicolumn{2}{|c|}{$\begin{array}{l}\text { L-Box } \\
\mathbf{H}_{2} / \mathbf{H}_{1}\end{array}$} \\
\hline & $\begin{array}{l}\text { Resultado } \\
\text { obtido }\end{array}$ & $\begin{array}{l}\text { Valor de } \\
\text { referência }\end{array}$ & $\begin{array}{l}\text { Resultado } \\
\text { obtido }\end{array}$ & $\begin{array}{l}\text { Valor de } \\
\text { referência }\end{array}$ & $\begin{array}{l}\text { Resultado } \\
\text { obtido }\end{array}$ & $\begin{array}{l}\text { Valor de } \\
\text { referência }\end{array}$ & $\begin{array}{l}\text { Resultado } \\
\text { obtido }\end{array}$ & $\begin{array}{l}\text { Valor de } \\
\text { referência }\end{array}$ \\
\hline $1: 3$ & $620 / 600$ & \multirow{3}{*}{$600 / 750$} & 4,31 & \multirow{3}{*}{2 a 7} & 13,92 & \multirow{3}{*}{5 a 15} & 0,82 & \multirow{3}{*}{$\begin{array}{c}0,80 \mathrm{a} \\
1,00\end{array}$} \\
\hline $1: 4,5$ & $610 / 590$ & & 3,30 & & 12,73 & & 0,82 & \\
\hline $1: 6$ & $600 / 590$ & & 5,93 & & 14,19 & & 0,86 & \\
\hline
\end{tabular}

Figura 4 - Diagrama de dosagem do CCV

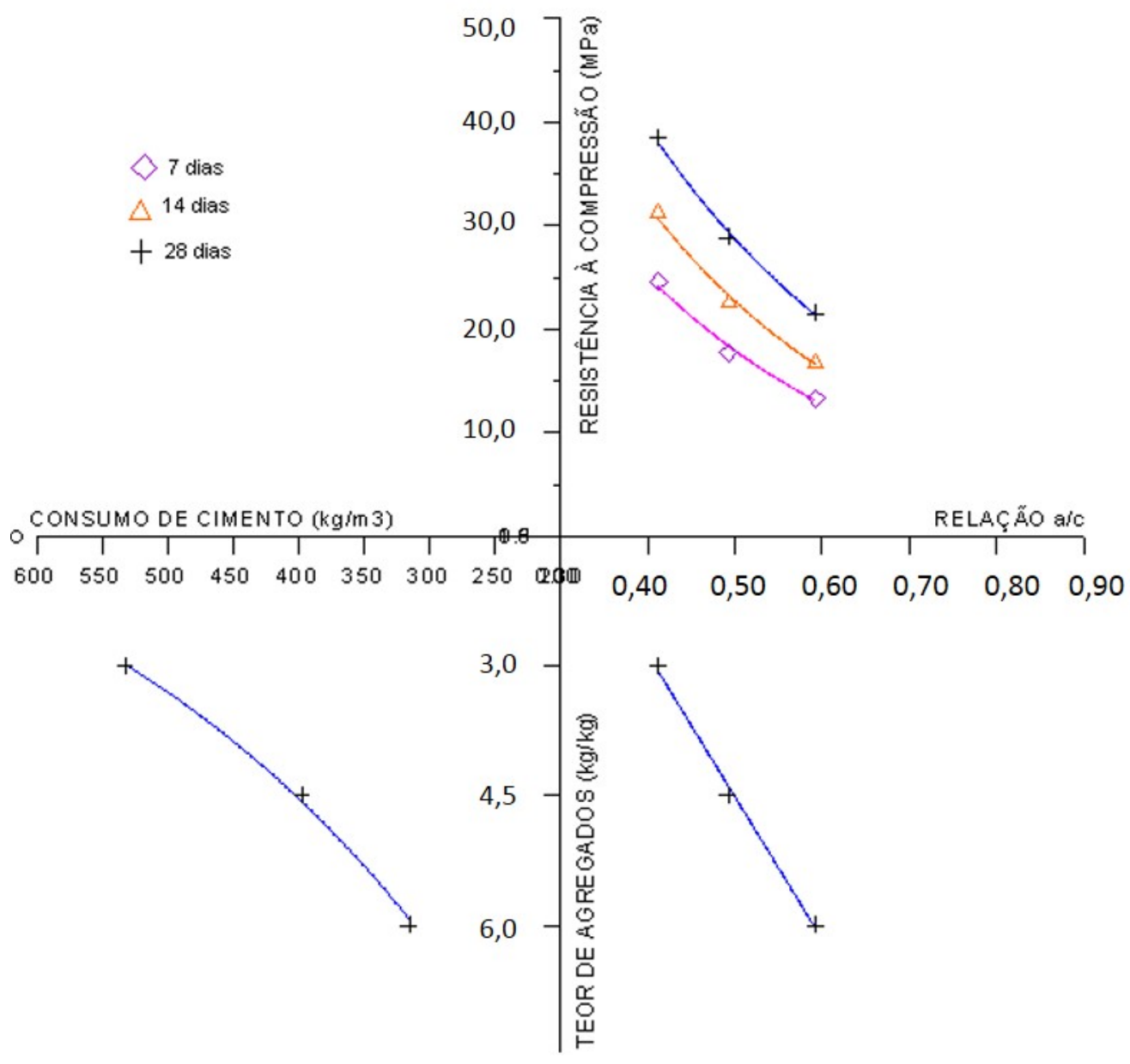


Figura 5 - Diagrama de dosagem do CAA

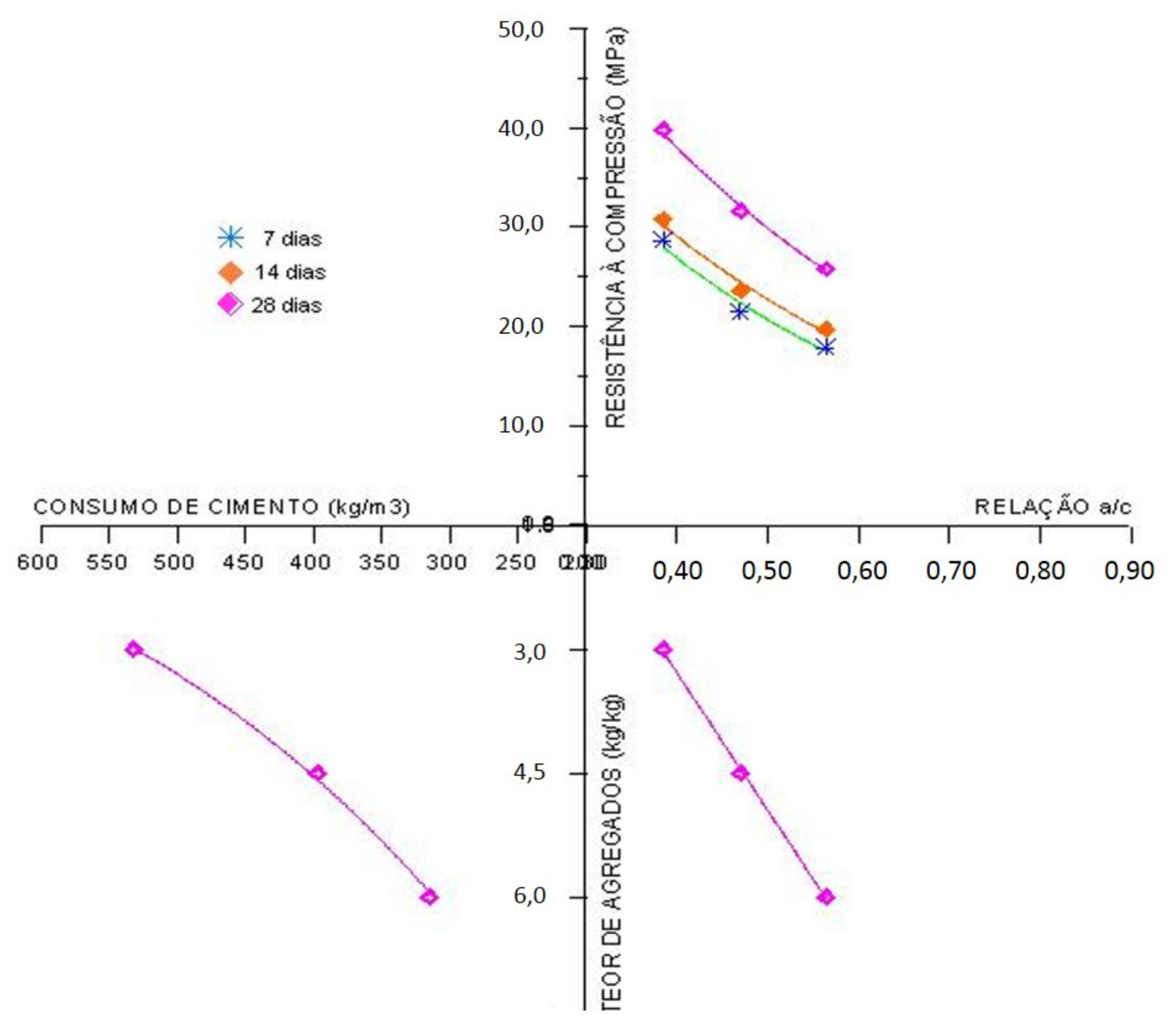

Figura 6 - Consumo de cimento para cada classe de resistência dos concretos

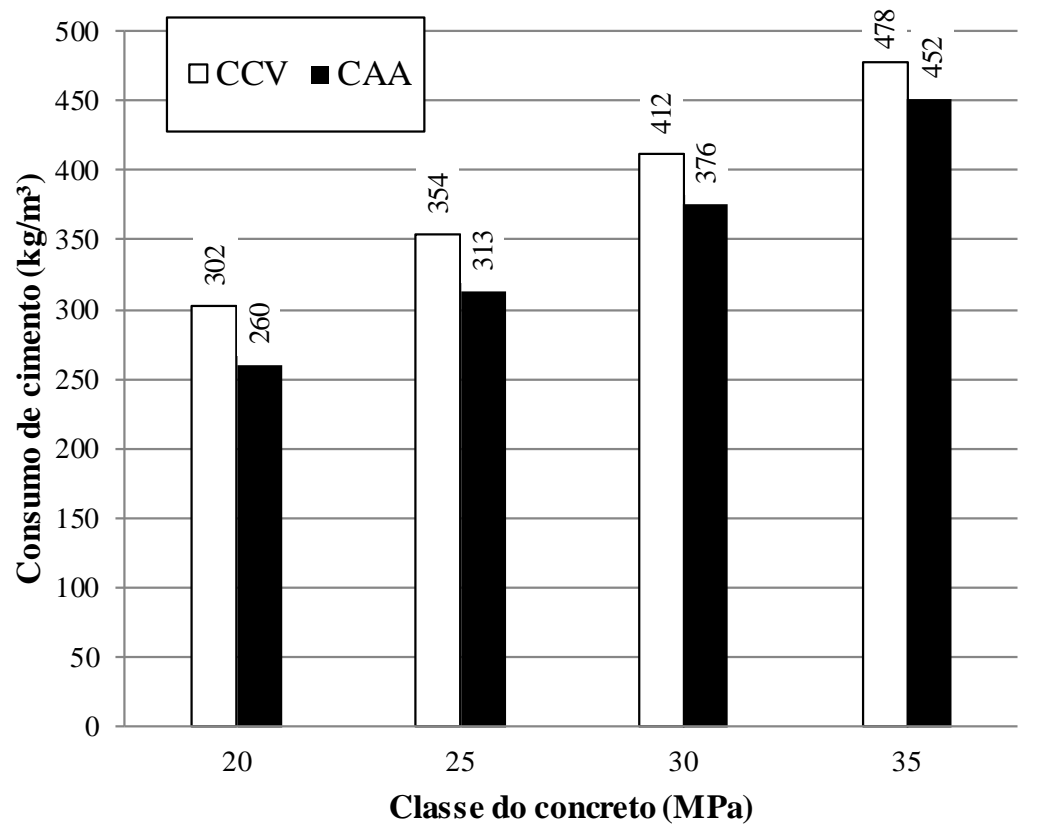




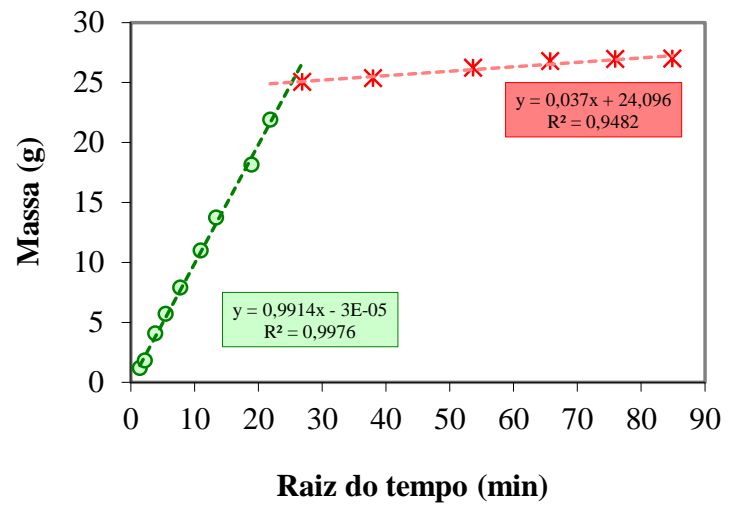

(a) $\mathrm{CCV}$

Ao observar a Figura 7 nota-se que o CAA demorou muito mais para passar da fase de absorção para a fase de saturação. Esse comportamento manteve-se para todos os traços, indicando que o fechamento da porosidade do CAA, obtida pela presença de EGF em substituição à areia, faz com que haja redução de sua capilaridade e, por consequência, uma taxa de absorção capilar menor. Resultados semelhantes também foram observados por outros autores, tais como Sua-Iama e Makul (2013), Bartholomei (2013) e Benaichaa et al. (2015).

Uma melhor análise dos dados pode ser feita observando-se as taxas de absorção calculadas para os diferentes traços de cada concreto na Tabela 7 , em que se evidencia redução da taxa de absorção do CCV com relação ao CAA. Nota-se ainda que, conforme foi aumentando a proporção de agregados+EGF em relação à massa de cimento, as taxas de absorção também foram aumentando. Esse comportamento já era esperado, pois os traços com menor quantidade de cimento denotam concretos mais porosos e, portanto, com maior facilidade de absorção de água.

Ao calcular a variância das taxas de absorção, de acordo com o tipo de concreto, dos diferentes traços e da interação entre os tipos de concretos e os traços (Tabela 8), verificou-se que todos os efeitos são estatisticamente significativos. Essa avaliação mostra que o fechamento da porosidade da matriz do CAA dificulta a absorção de água, o que é um efeito benéfico à durabilidade das estruturas de concreto. Comparativamente ao $\mathrm{CCV}$, as taxas de absorção do CAA são muito inferiores, ficando aproximadamente 50\% menores para todos os traços, conforme ilustra a Figura 8.

Ao avaliar a resistência capilar dos concretos ensaiados, nota-se mais uma vez o efeito benéfico

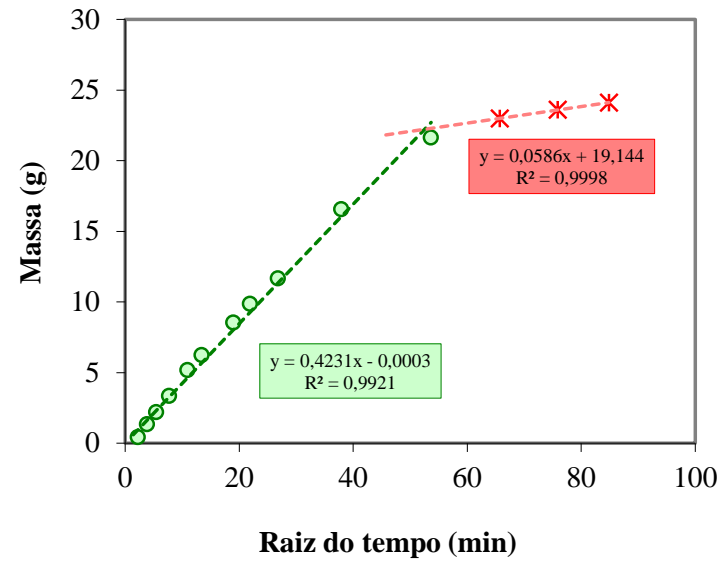

(b) CAA

do CAA em relação aos CCV, conforme dados da Tabela 9. Quanto menor a proporção de agregados+EGF em relação ao cimento, maior é sua resistência capilar, ou seja, maior é a dificuldade de absorção capilar de água, obviamente em função do maior empacotamento gerado pelo volume de cimento das misturas. Para os CAAs esse efeito fica mais pronunciado porque parte dos agregados miúdos também foi substituída por um material fino com propriedades aglomerantes, a EGF.

Os resultados da análise de variância (ANOVA) dos fatores influentes na resistência capilar dos concretos, descritos na Tabela 10, mostram que somente a interação entre tipo de concreto e traço não é estatisticamente significativa para alteração da resistência capilar. Provavelmente isso se deve ao comportamento benéfico do enriquecimento do traço para ambos os tipos de concreto. Porém, isoladamente, tanto o efeito do traço quanto o do tipo de concreto são significativos, ou seja, é correto dizer que os CAAs contendo EGF são mais resistentes à absorção de água, e esse comportamento é melhor à medida que enriquece o traço das misturas. Na Figura 9 observa-se graficamente a influência do tipo de concreto na resistência capilar, sendo essa propriedade aproximadamente $30 \%$ superior para o CAA em relação ao $\mathrm{CCV}$.

A avaliação da penetração de íons cloreto através do método da C 1202 (AMERICAN..., 2012) tem como resultado a carga elétrica passante nos concretos. Os resultados que podem ser observados na Tabela 11 mostram que, para ambos os concretos, quanto mais ricos são os traços, menor é a carga passante e, por correlação, menor é a penetração de íons cloreto. Verifica-se também que o CCV resultou em cargas passantes bem superiores 
ao CAA, ou seja, mais uma vez o efeito do empacotamento da mistura, gerado pela presença da EGF, resultou em um efeito benéfico em termos de durabilidade do produto final. Os resultados obtidos estão de acordo com outros estudos, tais como
Yazici (2008) e Uysala, Ylmaza e Ipekb (2012), que também observaram redução da penetração de cloreto nos CAAs contendo adições em relação aos CCVs.

Tabela 7 - Taxa de absorção por tipo de concreto e por traço $\left[\left(\mathbf{g} / \mathrm{cm}^{2} \mathbf{h}^{1 / 2}\right) \times \mathbf{1 0}^{-3}\right]$

\begin{tabular}{c|c|c|c}
\hline \multirow{2}{*}{$\begin{array}{c}\text { Tipo de } \\
\text { concreto }\end{array}$} & \multicolumn{3}{|c}{ Traço } \\
\cline { 2 - 4 } & $\mathbf{1 : 3}$ & $\mathbf{1 : 4 , 5}$ & $\mathbf{1 : 6}$ \\
\hline CCV & 8,32 & 10,94 & 12,04 \\
CAA & 3,900 & 4,81 & 5,54 \\
\hline
\end{tabular}

Tabela 8 - Análise da variância da influência dos resultados das taxas de absorção

\begin{tabular}{c|c|c|c|c|c|c}
\hline Fator & $\begin{array}{c}\text { Soma } \\
\text { quadrada }\end{array}$ & $\begin{array}{c}\text { Graus de } \\
\text { liberdade }\end{array}$ & $\begin{array}{c}\text { Média } \\
\text { quadrada }\end{array}$ & Teste F & Valor-p & Significância \\
\hline Tipo de concreto & 145,8661 & 2 & 72,6831 & 451,1864 & 0,0000 & Significativo \\
Traço & 13,62008 & 2 & 6,8100 & 42,5550 & 0,0000 & Significativo \\
Tipo de concreto x traço & 4,7469 & 4 & 1,1867 & 7,4157 & 0,0063 & Significativo \\
Erro & 1,4402 & 9 & 0,1600 & & & \\
Total & 165,6734 & 17 & 80,8340 & & & \\
\hline
\end{tabular}

Nota: Legenda:

Teste $\mathrm{F}=$ média quadrada do tipo de cimento/ média quadrada do erro; e

Valor $-\mathrm{p}=$ probabilidade, distribuição $\mathrm{t}$ de Student.

Figura 8 - Efeito da interação entre o tipo de concreto e o traço na taxa de absorção

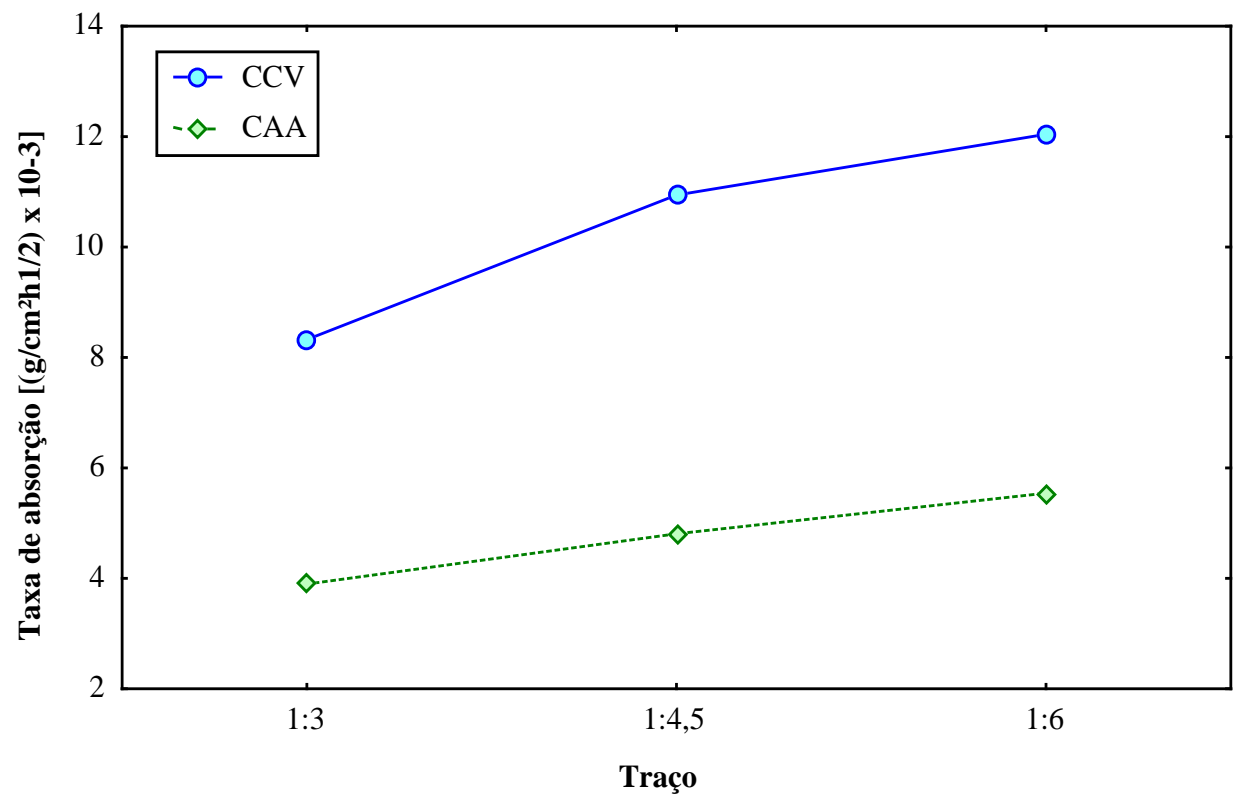

Tabela 9 - Resistência capilar medida nos corpos de prova em função do tipo de concreto e do traço $\left[\left(\mathrm{h} / \mathrm{m}^{2}\right) \times 10^{-5}\right]$

\begin{tabular}{c|c|c|c}
\hline \multirow{2}{*}{ Tipo de concreto } & \multicolumn{3}{|c}{ Traço } \\
\cline { 2 - 4 } & $\mathbf{1 : 3}$ & $\mathbf{1 : 4 , 5}$ & $\mathbf{1 : 6}$ \\
\hline CCV & 25,107 & 15,656 & 12,379 \\
CAA & 75,550 & 57,020 & 53,639 \\
\hline
\end{tabular}


Tabela 10 - Análise da variância da influência dos resultados de resistência capilar dos concretos

\begin{tabular}{c|c|c|c|c|c|c}
\hline Fator & $\begin{array}{c}\text { Soma } \\
\text { quadrada }\end{array}$ & $\begin{array}{c}\text { Graus de } \\
\text { liberdade }\end{array}$ & $\begin{array}{c}\text { Média } \\
\text { quadrada }\end{array}$ & Teste F & Valor-p & Significância \\
\hline Tipo de concreto & $7.373,9130$ & 2 & $3.686,9560$ & 106,7213 & 0,0000 & Significativo \\
\hline Traço & 541,7712 & 2 & 270,8860 & 7,8410 & 0,01067 & Significativo \\
\hline $\begin{array}{c}\text { Tipo de concreto x } \\
\text { Traço }\end{array}$ & 202,6435 & 4 & 50,6610 & 1,4664 & 0,2901 & $\begin{array}{c}\text { Não } \\
\text { significativo }\end{array}$ \\
\hline Erro & 310,9277 & 9 & 34,5752 & & & \\
\hline Total & $8.429,2554$ & 17 & $4.043,0780$ & & & \\
\hline
\end{tabular}

Nota: Legenda:

Teste $\mathrm{F}=$ média quadrada do tipo de cimento/ média quadrada do erro; e

Valor $-p=$ probabilidade, distribuição t de Student.

Figura 9 - Efeito do tipo de concreto na resistência capilar

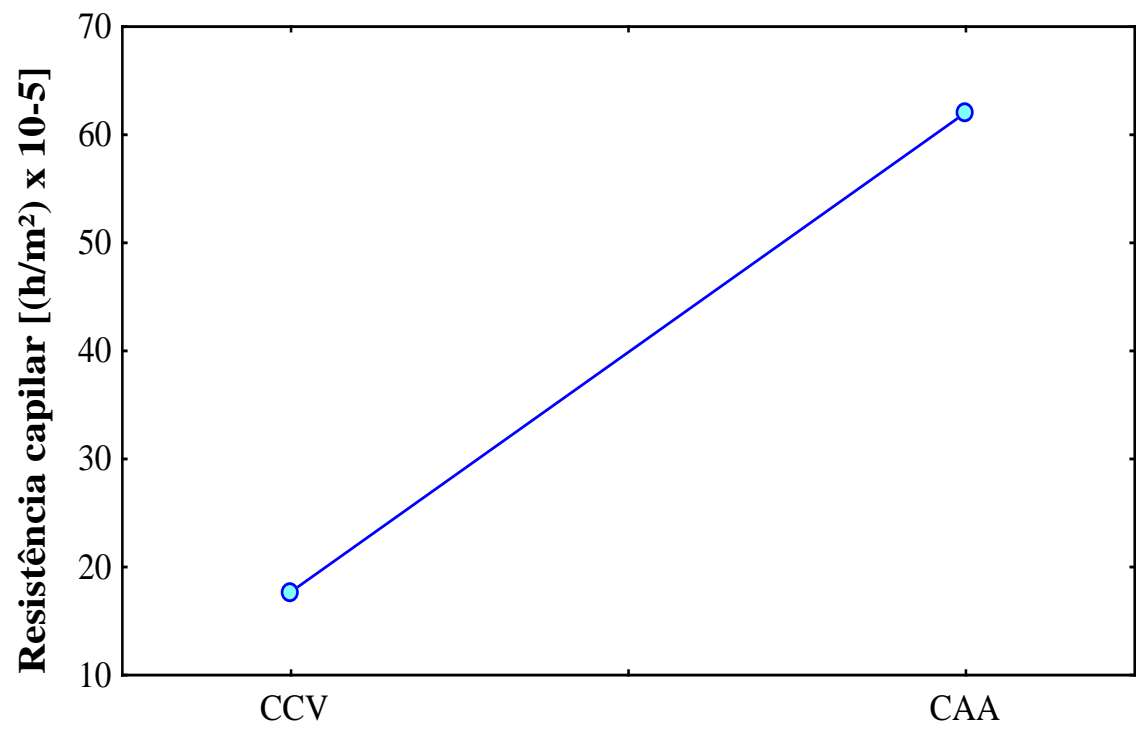

Tipo de concreto

Uma avaliação mais apurada dos dados, através da análise da variância (ANOVA), mostrou que realmente os traços e o tipo de concreto influenciam significativamente na alteração da carga elétrica passante, mas a interação entre ambos não tem influência significativa, conforme pode ser observado na Tabela 12. A interação que não foi considerada significativa mais uma vez é resultante do comportamento benéfico do aumento da quantidade de cimento para ambos os concretos no que diz respeito à penetração de cloreto na matriz.

O gráfico apresentado na Figura 10 mostra que nenhum dos traços produzidos com CAA possui carga passante alta, ou seja, alto risco de penetração de cloreto, contrariamente ao que se vê para o traço 1:6 no CCV. O traço mais rico do CAA (1:3) apresentou como resposta baixo risco à penetração de cloreto, ficando a carga passante em torno de 19 Coulombs $\times 10^{-3}$. Para o mesmo traço, o CCV resultou em carga passante de aproximadamente 30 Coulombs $\times 10^{-3}$, ou seja, mais de $60 \%$ superior.

\section{Avaliação dos custos}

As análises do comportamento dos concretos produzidos com EGF, tanto no estado fresco, quanto no estado endurecido e durabilidade, demonstraram seu comportamento benéfico e promissor. Os resultados obtidos no estudo evidenciaram que a EGF é um material que auxilia na obtenção da viscosidade adequada e pode ser empregado como modificador de viscosidade em CAA, sem prejudicar propriedades mecânicas e de durabilidade. 
Tabela 11 - Carga passante medida nos corpos de prova em função do tipo de concreto e do traço (Coulombs $\times 10^{-2}$ )

\begin{tabular}{c|c|c|c}
\hline \multirow{2}{*}{ Tipo de concreto } & \multicolumn{3}{|c}{ Traços } \\
\cline { 2 - 4 } & $\mathbf{1 : 3}$ & $\mathbf{1 : 4 , 5}$ & $\mathbf{1 : 6}$ \\
\hline CCV & 30,51 & 35,37 & 44,21 \\
CAA & 18,92 & 27,89 & 32,89 \\
\hline
\end{tabular}

Tabela 12 - Análise da variância da influência dos tipos de concreto e dos traços nos resultados de carga passante

\begin{tabular}{c|c|c|c|c|c|c}
\hline Fator & $\begin{array}{c}\text { Soma } \\
\text { quadrada }\end{array}$ & $\begin{array}{c}\text { Graus de } \\
\text { liberdade }\end{array}$ & $\begin{array}{c}\text { Média } \\
\text { quadrada }\end{array}$ & Teste F & Valor-p & Significância \\
\hline Tipo de concreto & 450,1333 & 2 & 225,0666 & 13,4305 & 0,0020 & Significativo \\
\hline Traço & 874,8578 & 2 & 437,4289 & 26,1029 & 0,0002 & Significativo \\
\hline Tipo de concreto x traço & 111,6619 & 4 & 27,9155 & 1,6658 & 0,2408 & Não significativo \\
\hline Erro & 150,8207 & 9 & 16,7579 & & & \\
\hline Total & 1587,4737 & 17 & 707,1688 & & & \\
\hline
\end{tabular}

Nota: Legenda:

Teste $\mathrm{F}=$ média quadrada do tipo de cimento/média quadrada do erro; e

Valor $-p=$ probabilidade, distribuição t de Student.

Figura 10 - Efeito do traço e do tipo de concreto na carga passante

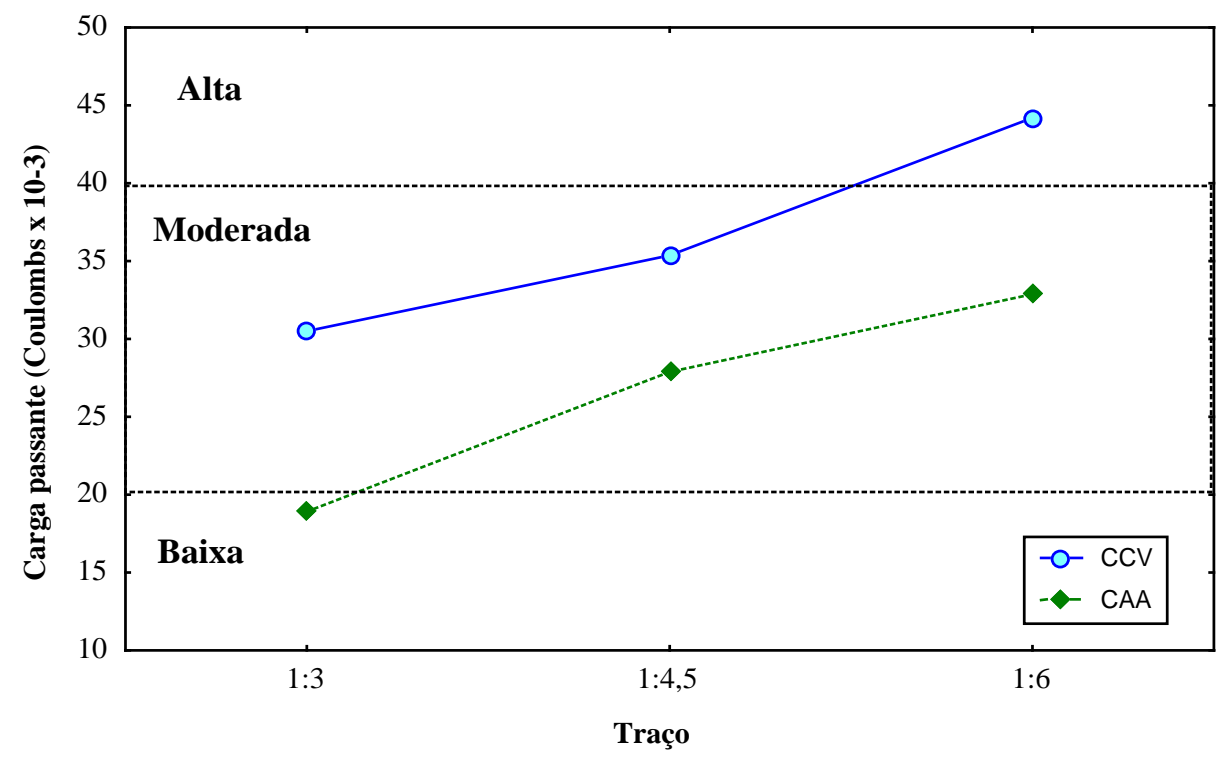

Contudo, um fator determinante na escolha de um material para a construção civil são os custos. Neste trabalho foram comparados os custos por metro cúbico do CAA confeccionado com EGF e os custos do CCV. Essa avaliação foi feita considerando todos os materiais que compõem os dois concretos, de acordo com o custo por metro cúbico e o custo para cada MPa, supondo que a EGF tenha custo igual ao de um filler calcário (análise superestimada de custo, já que a EGF não é ainda um material disponível para uso). A Figura 11 apresenta graficamente os resultados obtidos.

Os CAAs são, de modo geral, comercializados a custos superiores aos CCVs. O emprego de um volume maior de aditivos químicos para a produção de CAAs é fator determinante para que seu custo seja superior. No caso dos concretos avaliados na presente pesquisa o percentual de aumento por metro cúbico de concreto do CAA em relação ao CCV fica em torno de 28\% (28,4\%, 27,9\%, 28,0\% e $29,3 \%$ ). Ao comparar esse percentual de aumento com o encontrado por outros autores que confeccionaram CAAs com filler calcário, verificase que se trata de um crescimento razoável. Para se ter ideia, Tutikian (2004) determinou diferenças entre $40,8 \%$ a 45,0\% para resistências de até 40 MPa; para Manuel (2005), chegaram a 33,8\%. 
Figura 11 - Custos dos concretos

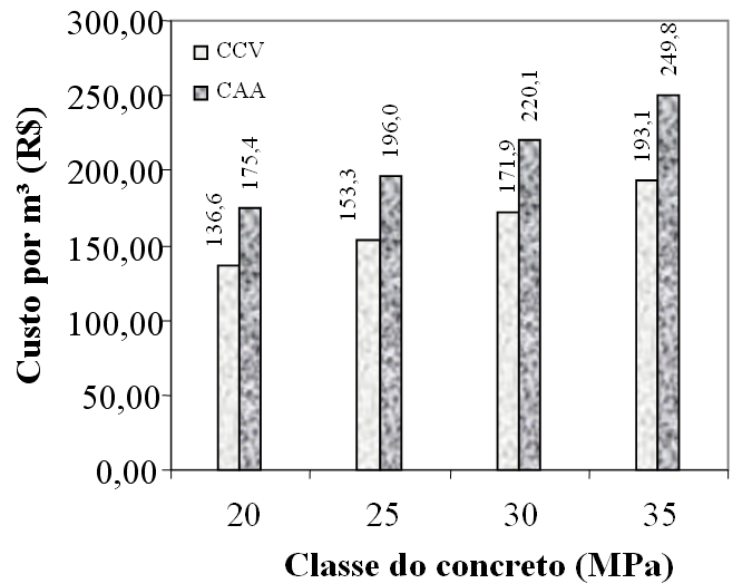

(a) Custo por $\mathrm{m}^{3}$ de concreto

Mesma tendência foi observada quando a análise foi feita em relação ao aumento de custo correlacionado ao aumento da resistência à compressão.

Contudo, a análise de custos aqui apresentada não contempla questões como mão de obra, prazo e equipamentos, que são características que resultam em vantagem econômica do CAA em relação ao CCV (OKAMURA; OZAWA; OUCHI, 2000; FERREIRA, 2001).

Além disso, no longo prazo, questões que envolvem manutenção, em decorrência da perda de durabilidade, também podem aumentar os custos envolvidos em estruturas confeccionadas com CCVs, uma vez que os resultados obtidos neste trabalho evidenciaram a superioridade dos CAAs em termos de resistência capilar e penetração de íons cloreto.

\section{Conclusões}

O estudo do emprego de EGF na produção de CAA mostrou que esse resíduo, quando em granulometria compatível com a do cimento, pode auxiliar na obtenção da viscosidade adequada. Todos os ensaios realizados no estado fresco para os CAAs mostraram que a EGF pode desempenhar bem esse papel, resultando em concretos com boa fluidez e sem segregação.

Quanto à resistência à compressão, verificou-se que, em função do fechamento da porosidade proporcionado pela EFG, um material fino que substitui o agregado miúdo em 35\%, o CAA resultou em resistências superiores ao CCV, havendo ganhos de até $34 \%$ aos 7 dias e de $20 \%$ aos 28 dias. Salienta-se que não foi contemplado o efeito pozolânico da EGF, que pode tornar o

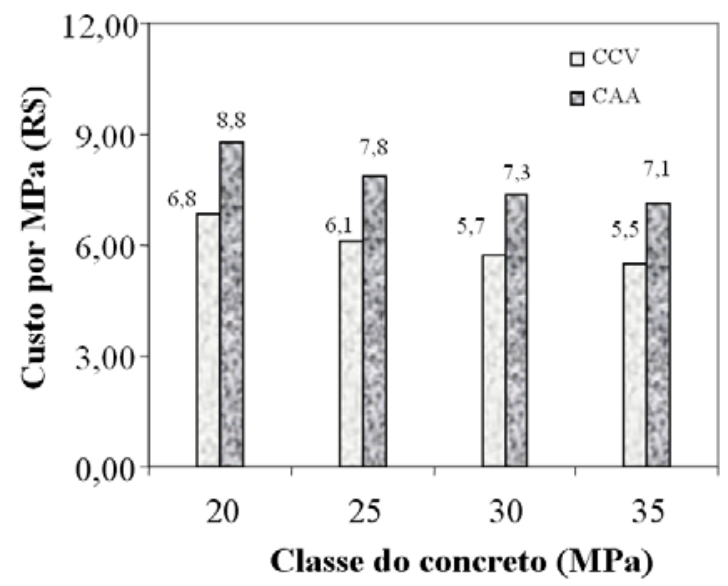

(b) Custo por $\mathrm{MPa}$

desempenho na resistência à compressão dos CAAs bem superior em idades mais avançadas.

Os ensaios de durabilidade evidenciaram melhora nas propriedades do CAA em relação ao CCV. Na avaliação da absorção de água por sucção capilar verificou-se que a pior situação para o CAA comparada à melhor situação para o CCV ainda resulta numa taxa de absorção 33\% inferior. A resistência capilar do CAA foi aproximadamente $70 \%$ superior à resistência capilar do CCV. Também se verificou redução significativa da carga passante no ensaio de penetração de íons cloreto do CAA em relação ao CCV, o que, por correlação, significa dizer que o CAA tem menor permeabilidade aos íons cloreto.

A avaliação dos custos dos concretos demonstrou que o CAA confeccionado com EGF pode ser até 29\% mais caro que os CCVs, o que é uma elevação pequena se comparada ao aumento que se tem em CAAs confeccionados com outros modificadores de viscosidade. Entretanto, há de se salientar que esses custos ainda podem ser reduzidos se uma análise mais ampla for aplicada, uma vez que no estudo realizado não foram contempladas questões relativas à tecnologia de aplicação do CAA, que envolve menor quantidade de mão de obra e equipamentos e menor tempo de concretagem.

Enfim, pode-se dizer que a utilização da EGF para auxiliar na obtenção da viscosidade adequada em CAA é uma boa alternativa para consumir esse resíduo, que é gerado em grandes volumes e não possui uma destinação específica de uso. Os CAAs confeccionados com EGF mostraram-se viáveis em termos de propriedades no estado fresco, resistência mecânica, durabilidade e custos. 


\section{Referências}

\begin{abstract}
AMERICAN SOCIETY FOR TESTING AND
MATERIALS. ASTM C-1202: standard test method for electrical indication of concrete's ability to resist chloride ion penetration. Section 4 (Construction), v. 04.02, Philadelphia, 2012.
\end{abstract}

\section{ASSOCIAÇÃO BRASILEIRA DAS}

INDÚSTRIAS DE FERRO FUNDIDO E AÇO. A Indústria de Ferro-Fundido. Disponível em: <http://www.abifa.com.br>. Acesso em: 27 maio 2017.

ASSOCIAÇÃO BRASILEIRA DE NORMAS

TÉCNICAS. NBR 10004: resíduos sólidos: classificação. Rio de Janeiro, 2004.

\section{ASSOCIAÇÃO BRASILEIRA DE NORMAS}

TÉCNICAS. NBR 15823-1: concreto autoadensável: parte 1: classificação, controle e aceitação no estado fresco. Rio de Janeiro, 2010a.

\section{ASSOCIAÇÃO BRASILEIRA DE NORMAS \\ TÉCNICAS. NBR 15823-2: Concreto}

autoadensável: parte 2: determinação do espalhamento e do tempo de escoamento: método do cone de Abrams. Rio de Janeiro, 2010b.

\section{ASSOCIAÇÃO BRASILEIRA DE NORMAS TÉCNICAS. NBR 15823-4: concreto} autoadensável: parte 4: determinação da habilidade passante: método da caixa L. Rio de Janeiro, 2010c.

\section{ASSOCIAÇÃO BRASILEIRA DE NORMAS \\ TÉCNICAS. NBR 15823-5: concreto} autoadensável: parte 5: determinação da viscosidade: método do funil V. Rio de Janeiro, 2010d.

\section{ASSOCIAÇÃO BRASILEIRA DE NORMAS} TÉCNICAS. NBR 15823-6: concreto autoadensável: parte 6: determinação da resistência à segregação: método da coluna de segregação. Rio de Janeiro, 2010e.

\section{ASSOCIAÇÃO BRASILEIRA DE NORMAS TÉCNICAS. NBR 5739: concreto: ensaio de compressão de corpos de prova cilíndricos de concreto. Rio de Janeiro, 2007.}

\section{ASSOCIAÇÃO BRASILEIRA DE NORMAS} TÉCNICAS. NBR 7211: agregados para concreto: especificação. Rio de Janeiro, 2009a.

\section{ASSOCIAÇÃO BRASILEIRA DE NORMAS} TÉCNICAS. NBR 8953: concreto para fins estruturais: classificação pela massa específica, por grupos de resistência e consistência. Rio de Janeiro, 2015.
ASSOCIAÇÃO BRASILEIRA DE NORMAS TÉCNICAS. NBR NM 52: agregado miúdo: determinação da massa específica e massa específica aparente. Rio de Janeiro, 2009b.

\section{ASSOCIAÇÃO BRASILEIRA DE NORMAS} TÉCNICAS. NBR NM 53: agregado graúdo: determinação da massa específica, massa específica aparente e absorção de água. Rio de Janeiro, 2009c.

ATTACHAIYAWUTH, A. et al. Improvement of Self-Compactability of Air-Enhanced SelfCompacting Concrete With Fine Entrained Air. Journal of Advanced Concrete Technology, v. 14, p. 55-69, 2016.

\section{BARTHOLOMEI, M. B. Estudo de Concreto} Autoadensável Com a Utilização de Materiais da Região de Manaus e Resíduos de Vidro Como Modificador de Viscosidade. Manaus, 2013. 114 f. Dissertação (Mestrado em Engenharia Civil) - Programa de Pós-Graduação em Engenharia Civil, Universidade Federal do Amazonas, Manaus, 2013.

BENAICHAA, M. et al. Influence of Silica Fume and Viscosity Modifying Agent on the Mechanical and Rheological Behavior of Self Compacting Concrete. Construction and Building Materials, v. 84, p. 103-110, 2015.

CECATTO, D. M. Avaliação da Utilização da Escória Granulada de Fundição (EGF) Como Substituição de Parte do Cimento em Concreto: propriedades mecânicas. Porto Alegre, 2003. 145 f. Dissertação (Mestrado em Engenharia) Faculdade de Engenharia Civil, Universidade Federal do Rio Grande do Sul, Porto Alegre, 2003.

DINAKAR, P.; SETHY, K. P.; SAHOO, U. C. Design of Self-Compacting Concrete With Ground Granulated Blast Furnace Slag. Materials \& Design, v. 43, p. 161-169, 2013.

FERREIRA, R. M. S. Betão Auto-Compactável: metodologia de composição. Guimarães, 2001. 178 f. Dissertação (Mestrado) - Escola de Engenharia do Minho, Universidade do Minho, Minho, 2001.

GARG, N. K. E. Self-Compacted Concrete. International Journal of Recent Research Aspects, v. 3, p. 116-117, 2016.

HELENE, P. R. L.; TERZIAN, P. Manual de Dosagem e Controle do Concreto. São Paulo: Pini, 1992.

KELHAM, S. A. A Water Absorption Test For Concrete. Magazine of Concrete Research, v. 40, n. 143, p. 106-110, 1988. 
KHAN, R. A.; SHARMA, A. Durability Properties of Self-Compacting Concrete Containing Fly Ash, Lime Powder and Metakaolin. Journal of Materials and Engineering Structures, v. 2, p. 206-212, 2015.

LEUNGA, H. Y. et al. Sorptivity of SelfCompacting Concrete Containing Fly Ash and Silica Fume. Construction and Building Materials, v. 113, p. 369-375, 2016.

MANUEL, P. J. Estudo da Influência do Teor de Argamassa no Desempenho de Concretos AutoAdensáveis. Porto Alegre, 2005. 178 f. Dissertação (Mestrado em Engenharia) - Escola de Engenharia, Programa de Pós-Graduação em Engenharia Civil, Universidade Federal do Rio Grande do Sul, Porto Alegre, 2005.

MOOSHER, L. Utilização de Resíduos Sólidos de Fundição Como Matérias-Primas Para Fabricação de Blocos de Concreto Para Pavimentação. São Leopoldo, 2013. 138 f. Dissertação (Mestrado em Engenharia Civil), Programa de Pós-Graduação em Engenharia Civil, Universidade do Vale do Rio dos Sinos, São Leopoldo, 2013.

OKAMURA, H.; OZAWA, K.; OUCHI, M. SelfCompacting Concrete. Structural Concrete, v. 1, p. 3-17, 2000.

PAGNUSSAT, D. T. Utilização de Escória Granulada de Fundição em Blocos de Concreto Para Pavimentação. Porto Alegre, 2004. 145 f. Dissertação (Mestrado em Engenharia) Faculdade de Engenharia Civil, Universidade Federal do Rio Grande do Sul, Porto Alegre, 2004.

PATILL, R. N.; MEHETRE, P. R.; PHALAK, K. $\mathrm{T}$. Cement Concrete Properties Incorporating Waste Foundry Sand. International Journal on Emerging Trends in Technology, v. 2, p. 221225, 2015.

RANJBAR, N. et al. Durability and Mechanical Properties of self-Compacting Concrete incorporating palm oil fuel ash. Journal of Cleaner Production, v. 112, p. 723-730, 2015.

RESCHKE, J. S. Escória Granulada de Fundição Utilizada Como Substituição ao Cimento em Concretos: avaliação de propriedades relacionadas com a durabilidade. Porto Alegre, 2003. 174 f. Dissertação (Mestrado em Engenharia) - Faculdade de Engenharia Civil, Universidade Federal do Rio Grande do Sul, Porto Alegre, 2003.
STROUP, W. W.; STROUP, R. D.; FALLIN, J. H. Cupola Slag Cement Mixture and Methods of Making and Using the Same. United States Patent 6,521,039. Publicado em: 18 fev. 2003. Disponível em:

<http://www.uspto.gov/web/offices/com/sol/foia/tt ab/2fissues/2002/113471.pdf>. Acesso em: 18 abr. 2017.

SUA-IAMA, G.; MAKULB, N. Use of Increasing Amounts of Bagasse Ash Waste to Produce SelfCompacting Concrete by Adding Limestone Powder Waste. Journal of Cleaner Production, v. 57, p. 308-319, 2013.

TAKADA, K. Influence of Admixtures and Mixing Efficiency on the Properties of SelfCompacting Concrete: the birth of selfcompacting concrete in the Netherlands. Delft, 2004. 220 f. Doctoral Thesis. Delft University of Technology, The Netherlands, 2004.

TORRESA, A.; BARTLETTB, L.; PILGRIMA, C. Effect of Foundry Waste on the Mechanical Properties of Portland Cement Concrete.

Construction and Building Materials, v. 135, p. 674-681, 2017.

TUTIKIAN, B. F. Método Para Dosagem de Concretos Auto-Adensáveis. Porto Alegre, 2004. 149 f. Dissertação (Mestrado em Engenharia Civil) - Escola de Engenharia, Programa de PósGraduação em Engenharia Civil, Universidade Federal do Rio Grande do Sul, Porto Alegre, 2004.

TUTIKIAN, B. F.; DAL MOLIN, D. C. C. Concreto Autoadensável. 2. ed. São Paulo: Pini, 2015.

UKPAKA, N. C. Concrete Produced With Foundry Waste as Partial Replacement For River Sand. Journal of Civil Engineering Research, v. 6, p. 1-6, 2016.

UYGUNOĞLUA, T.; TOPÇUB, I. B.; ÇELIKC, A. G. Use of Waste Marble and Recycled Aggregates in Self-Compacting Concrete For Environmental Sustainability. Journal of Cleaner Production, v. 84, p. 691-700, 2014.

UYSALA, M.; YLMAZA, K.; IPEKB, M. The Effect of Mineral Admixtures on Mechanical Properties, Chloride Ion Permeability and Impermeability of Self-Compacting Concrete. Construction and Building Materials, v. 27, p. 263-270, 2012.

YAZICI, H. The Effect of Silica Fume and HighVolume Class C Fly Ash on Mechanical Properties, Chloride Penetration and Freeze-Thaw Resistance of Self-Compacting Concrete.

Construction and Building Materials, v. 22, p. 456-462, 2008. 
YUNG, W. H.; YUNG, L. C.; HUA, L. H. A Study of the Durability Properties of Waste Tire Rubber Applied to Self-Compacting Concrete. Construction and Building Materials, v. 41, p. 665-672, 2013.

\section{Agradecimentos}

Os autores expressam sua gratidão ao Concelho Nacional de Pesquisa e à Coordenação de Aperfeiçoamento de Pessoal de Nível Superior, pela concessão de bolsas de auxílio financeiro, e à Escola Politécnica de Engenharia da Imed.

\section{Francieli Tiecher}

Programa de Pós-Graduação em Engenharia Civil | Faculdade Meridional | Rua Senador Pinheiro, 304, Vila Rodrigues | Passo Fundo - RS Brasil | CEP 99070-220 | E-mail: francieli.bonsembiante@imed.edu.br

\section{Paulo Manuel}

Departamento de Engenharia da Província de Luanda | Rua Massano de Amorim, Bairro Chicala I llha do Cabo - Luanda - Angola | E-mail: paulo.manuel@gmail.com

\section{Daniel Tregnago Pagnussat}

Departamento Interdisciplinar | Universidade Federal do Rio Grande do Sul | Rodovia RS 030, Km 92, no 11700, Campus Litoral Norte, Emboaba | Tramandaí - RS - Brasil | CEP 95590-000 | Tel.: (51) 3308-1332 | E-mail: danipag@gmail.com

\section{Denise Carpena Coitinho Dal Molin}

Departamento de Engenharia Civil, Escola de Engenharia | Universidade Federal do Rio Grande do Sul | Av. Osvaldo Aranha, 99, $3^{\circ}$ Andar, Cidade Baixa | Porto Alegre - RS - Brasil | CEP 90035-190 | Tel.: (51) 3308-3321 | E-mail: dmolin@ufrgs.br

\section{Angela Borges Masuero}

Departamento de Engenharia Civil, Escola de Engenharia | Universidade Federal do Rio Grande do Sul | E-mail: angela.masuero@ufrgs.br

\section{Revista Ambiente Construído}

Associação Nacional de Tecnologia do Ambiente Construído

Av. Osvaldo Aranha, 99 - 3o andar, Centro

Porto Alegre - RS - Brasil

$$
\text { CEP } 90035-190
$$

Telefone: +55 (51) 3308-4084

Fax: +55 (51) 3308-4054

www. seer. ufrgs. br/ ambienteconstruido

E-mail: ambienteconstruido@ufrgs.br 